\title{
ARTIGOS
}

http://dx.doi.org/10.5007/2175-8042.2018v30n53p18

\section{PRINCIPAIS CUIDADOS E INVESTIMENTOS CORPORAIS DE FREQUENTADORAS DE UMA ACADEMIA PARA MULHERES DE VITÓRIA/ES}

\author{
Camila Correia \\ Ivan Gomes²
}

\section{RESUMO}

O artigo aborda os principais cuidados e investimentos no corpo, a partir de frequentadoras de uma academia para mulheres. A pesquisa foi desenvolvida em uma academia exclusiva na cidade de Vitória/ES, por meio de observações das participantes, bem como entrevistas semiestruturadas com as alunas. O marco teórico privilegiou as contribuições de Gilles Lipovetsky sobre o corpo e a mulher moderna. No que se refere às análises, concluiu-se que os cuidados e os investimentos mais substanciais se pautaram na alimentação, exercícios físicos e procedimentos estéticos vinculados à busca de um corpo padronizado, e que é estimulado pelos trabalhos personalizados oferecidos pela academia. Também foi identificado um consumo de especialistas, sendo esses necessários na orientação desses investimentos.

Palavras-chave: Aparência corporal. Saúde da mulher. Consumo

1 Mestre em Educação Física. Professora da Rede Municipal de Serra. Vitória/Espírito Santo, Brasil.

E-mail: camilarissari@hotmail.com

2 Doutor em Ciências Humanas. Professor do Centro de Educação Física e Desportos na Universidade Federal do Espírito Santo (UFES).Vitória/Espírito Santo, Brasil. E-mail: ivanmgomes@hotmail.com 
maio/2018

\title{
MAIN CARE AND BODY INVESTMENT OF FREQUENTERS OF AN WOMEN'S GYM OF VITÓRIA/ES
}

\begin{abstract}
The article addresses the main care and investments in the body from attending a women's gym. The research was developed in an exclusive academy in the city of Vitória /ES, through participant observations, as well as semi-structured interviews. The theoretical framework privileged the contributions of Gilles Lipovetsky on the body and the modern woman. With regard to the analyzes, it is concluded that the most important care and investments were based on nutrition, physical exercises and aesthetic procedures linked to the search for a standardized body stimulated by the personalized work offered by the gym. A consumption of specialists has also been identified, and these are necessary in guiding these investments.
\end{abstract}

Keywords: Body appearance. Women health. Consumption

\section{PRINCIPALES CUIDADOS E INVERSIONES CORPORALES DE USUARIAS DE UN GIMNASIO PARA MUJERES DE VITÓRIA/ES}

\section{RESUMEN}

El artículo aborda los principales cuidados e inversiones en el cuerpo a partir de usuarias de un gimnasio para mujeres. La investigación fue desarrollada en un gimnasio exclusivo en la ciudad de Vitória/ES, por medio de observaciones participantes y entrevistas semi-estructuradas con las alumnas. El marco teórico privilegió las contribuciones de Gilles Lipovetsky sobre el cuerpo de la mujer moderna. En lo que respecta al análisis, se concluye que los cuidados y las inversiones más substanciales se pautaron en la alimentación, ejercicios físicos y los procedimientos estéticos vinculados a la búsqueda de un cuerpo padronizado y que es estimulado por los trabajos personalizados ofrecidos por el gimnasio. También fue identificado un consumo de especialistas, siendo estos necesarios en la orientación de esas inversiones.

Palabras clave: Apariencia corporal. Salud de la mujer. Consumo 


\section{INTRODUÇÃO}

O mercado de consumo relacionado às mulheres $^{3}$ se torna visível diante do significativo crescimento do número de academias, concomitante ao crescimento da indústria da beleza em conjunto com seus salões de beleza, clínicas estéticas, cirurgias plásticas e outras modalidades (FURTADO, 2007). Isso mostra o quanto tem aumentado a demanda nesses setores e a consequente busca pelo que é considerado belo. Junte-se a isso o desejo e a aparente possibilidade de um corpo perfeito, difundida por diferentes meios de informação, o que contribui para a procura por produtos e serviços disponíveis (DEL PRIORE, 2000).

O estimado corpo belo agrega a noção de saúde acolhendo características de bem-estar físico deliberado pela Organização Mundial de Saúde (OMS), como capacidade cardiovascular, força relacionada à definição muscular, flexibilidade e composição corporal magra (BAPTISTA; ZANOLLA, 2016). O capital econômico aqui se apresenta essencial na aquisição de bens disponíveis para a transformação do corpo. Uma alternativa para essa transformação se baseia no comprometimento com as academias de ginástica.

Nesse contexto, Azevedo (2011) expõe que as academias exclusivas para mulheres começam a se destacar. Borges et al. (2007) especificam que, com o aumento da venda e a comercialização de equipamentos e práticas corporais específicas para o segmento feminino, na tentativa também de atender às exigências do mercado das academias, foi perceptível o surgimento dessa nova tendência.

Essas academias surgem já no final do século XX, nos Estados Unidos. As franquias pioneiras nesse exclusivo mercado são as academias Curves e Contours. Atualmente, as franquias atingiram inúmeras unidades pelo mundo. Rocha (2011, p.46) expõe que as duas redes de academias possuem propostas parecidas, tanto no método de treinamento, quanto na forma de atrair e conquistar as clientes. De acordo com a autora,

[...] os treinos duram trinta minutos e priorizam as atividades cardiovasculares e de fortalecimento muscular, imprescindíveis para a perda de peso, a academia investe em um ambiente voltado para 'os gostos femininos'.

Azevedo (2011) e Rocha (2001), ao pesquisarem uma academia para mulheres na cidade de Porto Velho-Rondônia e Teresina-Piauí, respectivamente, verificaram, a partir das entrevistadas, que a maioria tem certa preocupação com a questão da estética corporal, possuem um tempo de prática considerável, frequentam a academia exclusiva com assiduidade, além de destacar o papel da mídia como um grande influenciador da sociedade, despertando novos valores, desejos e necessidades.

Diante das considerações expostas, o texto tem como objetivo identificar e analisar os principais cuidados e investimentos no corpo a partir das frequentadoras de uma academia para mulheres da cidade de Vitória/ES. Ressalta-se que o diálogo teórico do artigo

3 Esse artigo resulta de uma pesquisa financiada pela Fundação de Amparo à Pesquisa e Inovação do Espírito Santo/FAPES e está no escopo do projeto "A educação do corpo e em saúde nos projetos, práticas e narrativas identitárias na região metropolitana de Vitória” (Edital FAPES nº 04/2015). 
priorizou alguns elementos da abordagem de Gilles Lipovetsky sobre as características da mulher moderna, ao mesmo tempo, contamos com as suas contribuições para refletirmos e dialogarmos sobre os elementos que perpassam pelo corpo no contexto analisado. Essa articulação permitiu que estabelecêssemos aproximações e tensões entre o campo e tais argumentos teóricos. Para o autor, a mulher moderna também é conhecida como a terceira mulher, definida como um novo modelo que determina seu lugar e destino social. Isso significa que a dependência relativa dessa ao homem deixa de ser aquilo que a conduz nas democracias ocidentais.

Descrevendo sinteticamente, os dispositivos que constroem o modelo da terceira mulher são: "[...] desvitalização do ideal da dona-de-casa, legitimidade dos estudos e do trabalho femininos, direito de sufrágio, 'descasamento', liberdade sexual, controle da procriação [...]" (LIPOVETSKY, 1997, p. 232). O que o autor quer chamar atenção como uma das principais características da terceira mulher é a sua entrada no mundo do trabalho, sendo dotadas de protagonismo e autonomia. É a negação de uma identidade composta exclusivamente pelas funções de mãe e de esposa que compõem a condição da mulher pós-moderna, explica Lipovetsky (1997). Vale destacar que o teórico reconhece que, apesar da ruptura importante na história das mulheres, o modelo da terceira mulher não coincide de nenhuma maneira com o desaparecimento das desigualdades entre os sexos em matéria de orientação escolar, em relação à vida familiar, de remuneração e emprego.

Nesse sentido, o artigo estrutura-se da seguinte maneira: inicialmente, apresentaremos as estratégias metodológicas. Depois, abordaremos sinteticamente os argumentos de Gilles Lipovetsky sobre a mulher contemporânea, explicitando, na sequência, nossas análises nos seguintes tópicos: "Conhecendo o campo e as entrevistadas", "Os especialistas" e "Corpo, beleza e consumo em uma academia para mulheres".

\section{Caminhos metodológicos}

A pesquisa, de caráter qualitativo, foi realizada em uma academia para mulheres no município de Vitória/ES. Devido ao crescimento significativo do mercado das franquias, foi utilizado o estudo de caso (SEVERINO, 2007), com o objetivo de eleger um caso representativo e significativo dessas franquias internacionais. O projeto foi aprovado pelo Comitê de Ética em Pesquisa da xxxxx, no 926.931.

O instrumento para a produção dos dados foi realizado através de entrevista semiestruturada focalizada. Segundo Marconi e Lakatos (2007, p.279), esse tipo de entrevista ocorre "[...] quando há um roteiro de tópicos relativos ao problema a ser estudado e o entrevistador tem liberdade de fazer as perguntas que quiser, sobre razões, motivos, esclarecimentos.".

A escolha das entrevistadas baseou-se no critério de permanência mínima de seis meses na academia, além da disponibilidade para a entrevista. Na lista de quinze alunas ${ }^{4}$

4 Neste texto, os termos aluna, praticante e cliente serão compreendidos ao se referirem às mulheres que frequentam a academia exclusiva dentro de um contexto mercantil. O foco não é o trato pedagógico. 
que se adequavam nesse perfil, fornecida pela própria academia, somente onze retornaram positivamente no que se refere à disponibilidade para as entrevistas. $O$ critério de permanência ou a prática de exercícios pelas alunas da academia se justifica por ser um maior contato estabelecido com a instituição, além de ser um tempo reconhecido e instituído como viável a classificá-las como adeptas à atividade física (FREITAS et al., 2007). O consentimento das alunas ${ }^{5}$ foi formalizado por intermédio da assinatura de um Termo de Consentimento Livre e Esclarecido.

Além das entrevistas como produção de dados, foram realizadas observações, bem como registro em diário de campo. As observações participativas aconteceram, no mínimo, três vezes na semana, durante um período de seis meses. O Termo de Autorização Institucional foi devidamente assinado pela proprietária da academia para o acesso e elaboração dos dados. As observações foram de grande importância para a compreensão do cotidiano das alunas e dos profissionais, oferecendo um olhar mais próximo acerca da dinâmica dessa academia. Foram concretizadas com participação ativa nas atividades da academia e, em outro momento, era realizada a transcrição das observações para um diário de campo.

Para a análise dos dados, adotaram-se elementos da análise de conteúdo, organizando-os em dados por categoria para potencializar sua interpretação e compreensão. Bardin (2009) denomina essa técnica de análise categorial, pois funciona por operações de desmembramento do texto em unidades, em categorias. A partir das análises, foram elaboradas as seguintes categorias que se articulam: "Os especialistas", em que se analisa o consumo de especialistas, isso é, a contratação de profissionais na área da saúde, como os nutricionistas e médicos, e "Corpo, beleza e consumo em uma academia para mulheres", na qual se expõem os principais cuidados/investimentos das entrevistadas em prol do corpo perfeito.

\section{Conhecendo o campo e as entrevistadas}

Para uma melhor compreensão das categorias elaboradas, faz-se necessário apresentar, minimamente, as características da academia analisada e o perfil das onze alunas que aceitaram participar da pesquisa. A academia ${ }^{6}$ faz parte de uma franquia internacional e está localizada em um bairro nobre de Vitória/ES, presente há oito anos no mercado capixaba. Apresenta a metodologia dos trinta minutos, um circuito composto por exercícios de caráter funcional ${ }^{7}$ e exercícios realizados em máquinas.

5 Para preservar a confidencialidade, conforme previsto no TCLE, os nomes das mulheres citadas no trabalho foram substituídos por outros.

6 Uma forma de ilustrar o perfil das praticantes é mencionar o valor mensal cobrado pela academia, que gira em torno de $\mathrm{R} \$ 270,00$.

7 Baseia-se, principalmente, em movimentos naturais do ser humano, como pular, correr, puxar, agachar, girar e empurrar. O praticante ganha força, equilíbrio, flexibilidade, condicionamento, resistência e agilidade. Esses exercícios, às vezes, são realizados com sobrecarga. 
Além disso, possui equipamentos e treinamentos específicos para mulheres, além de um atendimento personalizado oferecido pela equipe profissional. Essa equipe é treinada pela franquia, sendo composta por três professoras de Educação Física que atendem na sala do circuito e musculação. É importante destacar que todas as profissionais são mulheres, desde a proprietária da unidade à responsável pela limpeza. Nenhum homem pode circular ou permanecer por muito tempo nessa academia ${ }^{8}$.

A respeito das alunas, a maioria reside no mesmo bairro em que a academia se localiza. A média de idade entre elas é de cinquenta anos. Em relação à escolaridade, oito alunas no total possuem ensino superior completo (dessas, três têm especialização e uma possui mestrado) e outras três possuem ensino superior incompleto. Ressalta-se que nenhuma entrevistada apresenta renda mensal familiar inferior a oito salários mínimos ${ }^{9}$. Vale destacar que somente duas alunas não trabalham, sendo uma universitária e a outra dona de casa. Para um melhor discernimento do poder aquisitivo das alunas, a tabela abaixo mostra quanto consomem/gastam com produtos e serviços destinados ao corpo.

Tabela 1- Consumo mensal das alunas

\begin{tabular}{cc}
\hline Entrevistadas & Consumo Mensal \\
\hline Márcia & $2.000,00$ \\
Sandra & 800,00 \\
Carla & 900,00 \\
Bruna & 900,00 \\
Cátia & $2.700,00$ \\
Adriana & $1.500,00$ \\
Luísa & 700,00 \\
Patrícia & $1.000,00$ \\
Fabiana & 500,00 \\
Amanda & $1.000,00$ \\
Rose & $1.000,00$ \\
\hline
\end{tabular}

Fonte: Informações prestadas das entrevistas.

Diante das informações contidas na tabela 1, pode-se afirmar que as alunas possuem boas condições financeiras. Em média, gastam R\$1.200,00 em produtos para a pele (áci-

8 Essa norma é proveniente da franquia, visível no trecho: "Fique à vontade e desinibida, com a presença exclusiva de mulheres na academia". A frase foi retirada do site http://contours.com.br/a-academia/, acessado em 13 de Dezembro de 2016. Além disso, esse tipo de característica é reforçado também na fala das entrevistadas, pois se sentem constrangidas pelo olhar masculino, o que é um grande motivador de escolha das mulheres por esse tipo de academia.

9 Segundo o Ministério do Trabalho e Emprego, o valor atual do Salário Mínimo é de R \$ 880,00 a partir de Janeiro de 2016. 
dos dermatológicos, protetor solar, peeling, creme antirrugas), suplementos alimentares, tratamentos em clínicas de estética, academia de ginástica, roupas fitness, depilação a laser, salão de beleza, remédios manipulados e alimentação específica receitada por nutricionista.

As alunas Cátia e Márcia chamaram atenção pelo valor investido nesses produtos e serviços. Em seu relato, Cátia comenta sobre seu consumo/gasto mensal:

“É mais de $\mathrm{R} \$ 2.000,00$, se eu contar com a dermatologista, com a minha médica de longevidade, os produtos, os remédios manipulados, só de manipulados sei que são $\mathrm{R} \$ 1.700,00$, botox, a consulta da minha médica de longevidade que o plano não cobre, pago $R \$ 400,00$ a consulta, acho que uns $R \$ 2.600,00 / R \$ 2.700,00$ vai por mês, eu disse que eu não posso ser uma mulher pobre, se não eu vou ficar velha." (Cátia, 59 anos, entrevista).

A partir dessa afirmação, é possível associar os cuidados com o corpo e com a beleza com o poder aquisitivo do indivíduo. Ou seja, aquelas mulheres que desejam adequar-se a um padrão juvenil precisam investir. Logo, para alcançar esses desejos, é necessário ter recursos financeiros e tempo para consumir produtos e serviços que de alguma forma contribuam para isso. É notório o poder de compra e o acesso desse público à informação, produtos e serviços variados no que se refere ao corpo. Como se observa, com base na tabela 1, os valores dos investimentos são variados, da mesma maneira que seu destino. A aluna Adriana, por exemplo, afirmou que gasta mais com roupas para usar na academia do que com roupas de sair, para uso no dia a dia.

A partir dos investimentos em produtos e serviços dedicados ao corpo, é possível afirmar que as mulheres entrevistadas estão interessadas e preocupadas com o embelezamento de seus corpos. A magnitude do interesse em se embelezar reflete no que a mulher pode pagar, em seu poder aquisitivo e na compreensão sobre o seu corpo, naquilo em que realmente deve ser investido.

A vivência no cotidiano da academia e o contato com as alunas permitiu ampliar o olhar e as interpretações que envolvem o corpo dessas mulheres. A seguir, serão apresentados e analisados o consumo de especialistas e os principais cuidados/investimentos das alunas, que se articulam, principalmente, com a escolha de uma academia exclusiva para mulheres.

\section{O consumo de especialistas}

A proposta dessa categoria é destacar a relação estabelecida entre alunas e especialistas, isto é, profissionais que são contratados pelas alunas de modo a contribuir em possíveis transformações no corpo, através de seus "conselhos". Essa categoria é importante, pois mostra como as entrevistadas acessam informações ou conhecimentos especializados para posteriormente realizar seus investimentos no corpo.

Inicialmente, antes de buscar informações ou/e especialistas, as alunas relataram a partir de que momento começaram a se preocupar com o corpo e o que realmente as influenciaram nessa decisão. 
"[...] Foi aos 17 anos, decidi mudar minha alimentação, seguia a orientação da minha família, da minha mãe de não comer muito sal, gordura, não comer fritura, mas aí agreguei outros conhecimentos que a medicina, sei lá, os estudos, as pesquisas vão nos indicando e fui sempre procurando esse caminho." (Cátia, 59 anos, entrevista, grifo nosso).

“[...] Acho que com meus 18 anos. Acho que a mídia, de uns anos pra cá, tá muito isso né, academia, todo mundo ficar bonita, acho que é isso. [Perguntamos que tipo de mídia] A televisão, minha mãe também é assinante de algumas revistas, a 'QUEM', 'CONTIGO', 'CARAS', minha mãe assina e eu acabo vendo." (Amanda, 20 anos, entrevista, grifo nosso).

É importante destacar que, dentre as onze entrevistadas, nove apresentam idade maior que quarenta anos e as demais abaixo dos trinta anos. As mulheres com maior faixa etária ressaltaram que o princípio da preocupação se constituiu a partir do momento em que começaram a sentir os efeitos do envelhecimento no corpo, além da influência da família e o ganho de peso após a gravidez. Aquelas com menor faixa etária relataram que a mídia - programas televisivos e revistas - foi responsável pela considerável extensão de suas preocupações com o corpo. Todavia, essas inquietações as aproximam independentemente da idade, no sentido da promoção de buscas por soluções e alternativas no combate à insatisfação corporal. O consumo e o acesso de informações provenientes da ciência (medicina) são ações cotidianas dessas mulheres.

Nessa direção, através das influências para a composição de um corpo ideal, as mulheres aderem a variadas práticas cotidianas:

[...] a angústia da idade e das rugas; obsessões com a saúde, com a 'linha', com a higiene: rituais de controlo (check-up) e de manutenção (massagens, sauna, desportos, regimes); cultos solares e terapêuticos (consumo de cuidados médicos e de produtos farmacêuticos), etc. (LIPOVETSKY, 1983).

Compreende-se que as alunas entrevistadas preocupam-se com o corpo principalmente devido aos efeitos e consequências do envelhecimento. É preciso "zelar permanentemente pelo seu bom funcionamento, lutar contra a sua obsolescência, combater os signos da sua degradação através de uma constante reciclagem cirúrgica, desportiva e dietética." (LIPOVETSKY, 1983, p. 58). O combate à "degradação" física e seus efeitos são permitidos por meio dos cuidados corporais.

À vista disso, pôde-se perceber o acesso das alunas a informações que de alguma maneira retardassem, principalmente, os efeitos da ação do tempo e o "papel" de mãe em seus corpos. Observa-se aqui uma aproximação das características da terceira mulher com as entrevistadas, que transparecem em seus relatos certa negação sobre o papel exclusivo de ser mãe, sendo esse um causador de efeitos negativos no corpo. A curiosidade e a motivação pela mudança corporal abrem caminhos para outras possibilidades, como a consulta com especialistas, por exemplo. 
Uma motivação para a procura por esses profissionais diz respeito às dietas alimentares que, geralmente, são orientadas por nutricionistas. Diante disso, cinco entrevistadas afirmaram, explicitamente, que frequentam ou frequentaram alguma vez esses profissionais:

“[...] Frequento nutricionista, tenho uma orientadora que me tira todas as dúvidas e me ensina como me alimentar direitinho, a mim e a minha família." (Cátia, 59 anos, entrevista).

“[...] Sigo uma dieta, certinha com meu nutricionista, tem mais de um ano já, que tô fazendo direitinho, às vezes dou uma 'derrapadinha' (risos)." (Amanda, 20 anos, entrevista).

As demais entrevistadas, mesmo que não tenham comentado ou realmente não tenham tido orientação de um nutricionista, afirmaram que já fizeram dieta em algum momento, ainda que por conta própria. A própria academia oferece o serviço de orientação nutricional. Para tanto, há uma sala especialmente dedicada ao atendimento das alunas por uma nutricionista. Outro fato evidente no relato das entrevistadas refere-se à solicitação de especialistas na área da estética. Alguns procedimentos estéticos, como o botox, o lifting, a drenagem linfática e os cremes dermatológicos, foram recorrentes em suas falas:

"[...] Faço estética, frequento estética, que tem massagens, drenagens. Drenagem eu faço toda semana. Na pele, eu frequento minha dermatologista quatro vezes ao ano, eu vou lá faço uma geral, faço laser... Posso vir a fazer plástica, não agora, só quando tiver bem enrugada, mas agora eu não pretendo. Peço orientação da minha dermatologista, 'o que eu posso fazer?' Ela sempre fala pra mim, 'você não vai precisar fazer plástica nunca, se você seguir a minha orientação direitinho'. Então eu uso ácido, eu uso os creminhos que ela me indica, filtro solar até de noite, duas vezes por ano eu faço laser, botox, eu tento manter aquilo que ela me orienta. Sou muito fiel a minha dermatologista." (Cátia, 59 anos, entrevista, grifo nosso).

A frase grifada denota um tipo de fidelidade e confidencialidade na relação entre um mestre e seus discípulos, que juram fidelidade ao seu mestre e tentam reproduzir e pôr em prática seus ensinamentos. As lições transmitidas pelo mestre são valiosas. Tempo e esforços não são medidos pelos discípulos, os quais almejam contemplar e alcançar a perfeição. Nessa perspectiva, como há o consumo de produtos e serviços atualmente, há também o consumo de especialistas. Esses se aproximam do que Bauman (2001) caracteriza como os conselheiros do mundo privado:

[...] Os conselhos que os conselheiros oferecem se referem à política-vida, não à Política com P maiúsculo; eles se referem ao que as pessoas aconselhadas podem fazer elas mesmas e para si próprias, cada uma para si - não ao que podem realizar em conjunto para cada uma delas, se unirem forças. (BAUMAN, 2001, p.77). 
Segundo o autor, os conselheiros cuidam para jamais pisarem fora da área delimitada do privado. Estão ligados às questões do viver bem e da política-vida10. Porém, quando o sujeito que solicitou as recomendações desses especialistas não está satisfeito, simplesmente o descarta:

“[...] Eu até fui numa nutricionista, não achei interessante, eu achei que ela tinha menos conhecimento do que eu na verdade, eu saí decepcionada, porque eu queria trabalhar nessa minha pré-diabetes, e ela não tinha um conhecimento pra poder me dar uma orientada legal." (Márcia, 62 anos, entrevista).

Dessa forma, o descontentamento de clientes 11 promove a demissão e, talvez, a procura e a contratação de outros conselheiros. Isso não acontece somente em relação aos especialistas, mas também na rotatividade encontrada nas academias de ginástica, na substituição de produtos de beleza e dos procedimentos estéticos, entre outros. Vale lembrar que "esta vastidão de especialistas e conselheiros privados, embora ofereçam informações diferenciadas e conflituosas, reforça a atribuição de responsabilidades aos indivíduos contemporâneos" (GOMES, 2008, p.59).

Observa-se o esforço da academia analisada em permanecer também como um conselheiro na vida das alunas. Para isso, permitem que os horários das aulas sejam planejados em prol das mesmas, autorizam que até mesmo "sessões de terapia" aconteçam na sala da gerência ou durante o treinamento com as professoras12. Sempre haverá uma roupa nova na loja de moda fitness, situada no primeiro andar da academia, um exercício novo para compor o treinamento da aluna, um "conselho" que, mesmo sendo pago, fará parte do cotidiano das mulheres que a frequentam. Esses elementos personalizados pretendem diminuir a evasão e constituir alunas "fiéis" aos seus conselhos e prescrições. Lipovetsky (1983) afirma que a personalização dos espaços prolifera a sedução dos consumidores, e essa sedução opera em função das motivações individuais de uma vida flexível cheia de opções. Até porque "[...] a mais custosa e irritante das tarefas que se pode pôr diante de um consumidor é a necessidade de estabelecer prioridades [...] A infelicidade dos consumidores deriva do excesso e não da falta de escolha" (BAUMAN, 2001, p. 75).

10 A política-vida está vinculada às estratégias presentes na sociedade de consumidores em que destacam o poder de autonomia dos sujeitos no sentido de que são eles os responsáveis pela resolução de tarefas e que estão articuladas com processos de responsabilização pessoal (BAUMAN, 2007).

11 Compreendemos que as relações das mulheres com a academia flutuam, sendo que em certos momentos essas se consideram "alunas" e necessitam do conhecimento, e em outros como "clientes", exigindo condições à academia em troca da sua permanência.

12 Durante o período de observação participante, notou-se que algumas conversas das alunas com as professoras possuíam um tom de confissão e desabafo sobre determinados assuntos pessoais, exercícios físicos e alimentação. As conversas mais recorrentes giravam em torno de frustações advindas de ações de "descontrole", isto é, a aluna que comeu demais no final de semana, a outra que faltou à academia. Nesse sentido, as mulheres esperavam das professoras, além de alguém para ouvir, por conselhos e soluções para as suas lamentações. 


\section{Corpo, beleza e consumo em uma academia para mulheres}

As informações analisadas anteriormente indicam que as alunas investem tempo e dinheiro para cuidar do corpo, na medida em que procuram por conselheiros para atingirem tal objetivo. Nessa assertiva, percebe-se o destaque e a relevância dos cuidados corporais em seu cotidiano.

Inicialmente, o destino dos maiores investimentos/cuidados das alunas com o corpo está relacionado, principalmente, com a alimentação. Os outros cuidados mais citados referem-se ao exercício físico e aos procedimentos estéticos. Diante disso, serão trabalhados esses três cuidados, uma vez que tiveram notável predomínio nos relatos. Em relação aos cuidados alimentares, observam-se as falas das alunas:

“[...] Alimentação, alimentação correta, sem gordura, sem açúcar, pra mim é isso, é cuidar do corpo." (Adriana, 51 anos, entrevista).

"[...] Eu particularmente cuido do corpo assim, alimentação e atividade física. Eu não sou de creme, meu negócio é comida e atividade física, eu acho que é isso, não eu não bebo, eu não fumo, nunca comi gordura." (Rose, 55 anos, entrevista).

Percebe-se certa preocupação com a ingestão de alimentos calóricos, ou seja, as alunas, ao se referirem à alimentação, citaram dietas baseadas em alimentos integrais, evitando aqueles ricos em gordura e açúcar. Além disso, Rose e Cátia mencionam a bebida alcoólica como elemento nocivo ao corpo. O discurso ${ }^{13}$ do bem estar condena a ingestão da bebida alcoólica, pois, assim como o fumo, são vícios prejudiciais ao estilo de vida saudável e à defesa corporal (TRIBESS, 2006). Nesse panorama, para se atingir os objetivos da juventude, beleza e saúde, deve-se reprimir a gula, mantendo alguma forma de dieta, controlando o vício do cigarro e do álcool, entre outros (LOVISOLO, 2006). Conforme o argumento do autor, há uma questão moral fortemente instituída.

Ao evitar o consumo desses alimentos calóricos, que às vezes são considerados literais "sacrifícios", as mulheres desejam emagrecer ou manter o corpo "na linha". O medo e a aversão à gordura corporal podem ser notados na fala desta aluna:

"[...] Eu tenho pavor a gordo, porque eu acho que é relaxamento, eu acho que é falta de vontade, pelo menos o meu marido, ele era lindo, era magro... Aí ele me fala assim 'é ansiedade!'... Que ansiedade que nada... Tira esse negocio da cabeça, sabe, então eu fico irritada. Ai ele diz, 'já passou tantas horas de comer, já estou ficando com dor de cabeça'... Aí falei, 'com esse monte de gordura que você tem nessas pernas, você acha que seu corpo tá precisando de alguma coisa?' Aí falei, 'você pode ficar numa cova, numa caverna um mês que você não vai morrer de fome'. Então, me irrita." (Rose, 55 anos, entrevista).

13 No campo da Educação Física existem críticas a esse tipo de perspectiva, por exemplo, o texto de Gomes (2008). 
Associar a obesidade com a falta de vontade é um discurso comum na atualidade. Ora, em uma sociedade em que os indivíduos são responsabilizados por seus cuidados, aquele que se encontra com excesso de peso é caracterizado como preguiçoso, negligente e irresponsável. A sociedade contemporânea, que preza pela flexibilidade e pela rápida mobilidade, começa a nutrir uma franca aversão pelos gordos, e a paixão tende a se transformar em um bem exclusivo daqueles considerados esbeltos (SANT'ANNA, 2001). Gomes (2006) expõe uma aproximação do obeso e da obesidade com a metáfora do "vagabundo", utilizada por Zygmunt Bauman ${ }^{14}$. Ele mostra a figura do obeso como o indivíduo que exibe dificuldade em se movimentar com a leveza característica da atual fase moderna. Dessa maneira, o "vagabundo" é aquele:

[...] com 'tremenda dificuldade' para se adequar à mobilidade exigida na sociedade contemporânea. As 'sempre novas' experiências e sensações presentes na leveza da sociedade de consumidores são percebidas como um fardo ainda maior para aqueles que possuem um peso excessivo no próprio corpo, como atesta a fragilidade da mobilidade do vagabundo. (GOMES, 2006, p. 47).

A obesidade e o obeso trazem consigo imagens e significações sociais que as vinculam a um lado pesado e lento. Além disso, permitem-se pensá-los como inadequação ao belo numa sociedade que a beleza significa disposição para se adequar às novidades (GOMES, 2006). Isso se articula ao que a aluna citada anteriormente considera negativo sobre seu cônjuge ${ }^{15}$. A caracterização pejorativa direcionada ao marido também se relaciona ao que Fischler (1995) descreve como o estereótipo negativo do gordo. Este consiste no gordo depressivo, um irresponsável sem controle sobre si mesmo, que só suscita nos indivíduos reprovação, quando não a aversão.

A reprovação social (e familiar) dos obesos está vinculada ao entendimento de que possuem atitudes de irresponsabilidade e descontrole. A aversão aos obesos está diretamente ligada aos cuidados e anseios que as alunas possuem em relação ao próprio corpo. Ainda nesse viés, outra aluna também manifesta a sua insatisfação e negatividade contra as pessoas (nesse caso, seu esposo) com excesso de peso:

“[...] O meu marido, quando eu casei com ele, ele já era um veneno ambulante e é até hoje (risos). Ele tá lá colhendo o que ele planta, cheio de stents no coração, gordo, ferrado e não desperta. Por mais que eu converse com ele, tento ensinar, ele sempre tá deixando na minha mão a saúde dele." (Cátia, 59 anos, entrevista).

14 Zygmunt Bauman destaca essa metáfora para ilustrar quem são as vítimas e os heróis do capitalismo flexível, uma sociedade marcada pela constante mudança, onde o que vale é a habilidade de se mover. Nesse sentido, o autor denomina de turistas aqueles que recusam qualquer forma de fixação, movimentam-se em prol dos seus sonhos e fantasias, suas necessidades de consumo e seu estilo de vida. Já os ditos vagabundos são aqueles empurrados pelas "forças" e "incertezas" da sociedade contemporânea ou então os que não possuem as ferramentas necessárias para se mover quando se deseja. Movimentam-se em prol da sobrevivência.

15 Para além de um determinado ideal de corpo que transparece nas análises e apesar das entrevistadas se apresentarem como livres e independentes, ainda há uma forte relação e sujeição ao casamento. 
Macedo et al. (2015) argumenta que o sofrimento decorrente do corpo obeso é resultado de apontamentos que denotam como responsável por essa condição a própria pessoa que exibe o sobrepeso. A ideologia da saúde e do corpo perfeito leva a considerar as doenças que atingem e deformam a figura humana como sinônimo de fracasso pessoal (ORTEGA, 2003). Assim, frases como "ele tá colhendo o que ele planta" irão se repetir cada vez mais em um contexto marcado pela responsabilização individual.

Um dos efeitos que compõem a responsabilidade do indivíduo sobre si se configura no controle da própria alimentação, uma "vida regrada", conforme indicam as entrevistadas: "É cuidar bem da alimentação, saudável, fazer uma alimentação equilibrada, nada de excesso [...]" (Sandra, 59 anos, entrevista). Lipovetsky (1997, p. 141) afirma que a nossa época é testemunho de uma nova força social de normalização e de racionalização do corpo. Porém, seria equivocado situar essa lógica social no prolongamento da era das disciplinas. Isso é, no lugar das imposições e regulamentos uniformes, observa-se atualmente uma nebulosa rede de solicitações de produtos e de recomendações que expandem o campo da escolha, da iniciativa individual e dos programas à la carte.

[...] À quadrícula autoritária e dirigista sucedeu a desregulação consumista e desportiva com o seu cortejo de actividades ligadas à forma e à manutenção, a sua profusão de prescrições dietéticas e de métodos de emagrecimento, o seu supermercado de produtos anti-rugas.

Anteriormente, a disciplina pretendia afetar a intervenção da consciência e da vontade, em benefício de uma obediência cega e mecânica do corpo. O corpo treinado age idealmente sem pensamento nem reflexão, semelhante às rodas dentadas de uma máquina perfeita (LIPOVETSKY, 1997). Contudo, essa já não é a lógica que nos conduz em uma era em que a informação e a diversificação da oferta implicam quase fatalmente a escolha, a decisão e a participação dos indivíduos. Da mesma maneira que se estabelece a norma homogênea do corpo magro e jovem, mais os indivíduos são compelidos a se informar sobre as "novidades", a fazer escolhas entre as opções dietéticas e desportivas que lhes oferecem. O indivíduo ator tomou lugar do indivíduo máquina. O indivíduo ator é aquele que valoriza regimes personalizados, autogestão de comportamentos alimentares, ou seja, aquele que está em sintonia com métodos de responsabilização pessoal em matéria de alimentação. A conquista do corpo ideal trouxe mecanismos de autocontrole ${ }^{16}$ que, para serem eficazes, não deixam de mobilizar a iniciativa, a consciência e motivação individual (LIPOVETSKY, 1997). Entende-se que existe um equilíbrio de antagonismos, pois, ao mesmo tempo em que as mulheres possuem significativa liberdade e autonomia em gerir seus corpos, há também a implicação de normatizações tendo como parâmetro um modelo ideal de corpo.

16 Ressaltamos que o próprio Foucault tinha clareza sobre a "migração" de uma sociedade disciplinar para uma sociedade de controle, onde a sedução, mais que a repressão, ajuda a compreender os modos de subjetivação contemporâneos. 
Posterior à alimentação, o exercício físico foi um dos cuidados mais citados pelas alunas: "[...] meu exercício, eu não abro mais a mão, eu tenho lido muito sobre exercício, tanto físico quanto mental, e já vi que não podemos abrir mão dele, pro nosso próprio bem" (Luísa, 57 anos, entrevista). Dessa forma,

[...] A estética da magreza ganhou, disso não há dúvida, mas, longe de engendrar uma racionalidade disciplinar, surge acompanhada de práticas instáveis e sismográficas que oscilam entre a atividade e a inactividade, a restrição e o excesso, a mobilização e o abandono, o controle e o abrandamento. Embora o código da magreza gere culpabilidade e ansiedade, apenas muito imperfeitamente consegue fabricar corpos dóceis, autocontrolados e conformes às normas. (LIPOVETSKY, 1997, p.143).

As sociedades contemporâneas ocidentais intensificam as prescrições relativas ao corpo, reforçam os princípios dietéticos e desportivos, mas, ao mesmo tempo, o universo do consumo exacerba os desejos e o "tudo e já" proporciona os impulsos e os entusiasmos passageiros, além de aumentar a aversão pelos esforços regulares e rigorosos (LIPOVETSKY, 1997). Contudo, o campo nos mostrou que as entrevistadas buscam o controle, isso é, são alunas que acompanham a academia desde que foi inaugurada. Isso significa dizer que são assíduas, comprometidas e tão pouco apresentam "aversão" pelos esforços regulares e rigorosos, como afirma o autor. Pelo contrário. Estão na busca do controle e do esforço para alcançar o corpo belo, embora não renunciem às tomadas de decisão envolvidas nas inúmeras escolhas proporcionadas pelo mercado e sua pragmática do consumo. A vigilância e o esforço para se manter "na linha" se materializam no momento em que as alunas faltam à academia. Pensamentos negativos e de culpa as fazem retomarem suas rotinas de exercícios físicos. Para exemplificar essa circunstância, comentaram sobre o que sentem quando faltam à academia:

"[...] Muito triste, hoje eu num vou poder vir, eu já tô com o coração apertadinho, com raiva da faxineira (risos). Eu gosto de vir todos os dias, eu procuro tirar um dia pra não malhar, mas às vezes nem tiro. Acho que sou um pouco até viciada." (Cátia, 59 anos, entrevista).

"[...] Ah, eu fico me sentindo culpada, 'ah eu num fui malhar', parece que tudo o que você fez durante a semana vai por água abaixo, mas ai tento pensar que não, um diazinho só. Mas eu só falto quando tem muita necessidade só ou quando a preguiça bate muito." (Amanda, 20 anos, entrevista).

As alunas se sentem culpadas e/ou tristes por faltar à academia e cada vez mais se responsabilizam, associando que, se deixarem de realizar seus exercícios físicos diários, estarão predispostas à preguiça e indisposição e, consequentemente, correm o risco de engordar. O último cuidado analisado para o alcance e manutenção desse corpo diz respeito aos procedimentos estéticos: 
"[...] Cuido do cabelo, da pele, se eu tiver que colocar um botox eu coloco, tô pensando em ano que vem fazer um lifting, então, mas eu não sou neurótica não, não tô procurando ninguém não, 'ah ela tá procurando juventude eterna' Isso não, eu procuro envelhecer, mas assim me olhar e dizer: 'tô feliz em me olhar mesmo com essa idade' É a minha maneira de olhar a vida." (Márcia, 62 anos, entrevista).

É notório que os procedimentos estéticos realizados pelas alunas não são acessíveis a qualquer classe social, como, por exemplo, em um país com tantas discrepâncias sociais como o Brasil. Em média, o valor17 da aplicação do botox, por exemplo, gira em torno de $R$ \$ 600,00 à R\$ 800,00. Nesse sentido, as ações estéticas apresentadas fortificam o poder de compra das mulheres que frequentam a academia exclusiva, aproximando-as também do perfil característico da mulher contemporânea de Lipovetsky. Além desses pequenos procedimentos, as alunas mencionaram que cogitaram a possibilidade ou já realizaram alguma intervenção cirúrgica estética. Sete entrevistadas responderam positivamente, porém somente duas alunas realizaram cirurgia plástica:

“[...] Eu já fiz, já coloquei silicone, já tirei porque meu organismo rejeitou, então eu fiquei sete anos com prótese na mama e depois rejeitou e tirei, ai depois coloquei outra marca, por baixo do músculo [...]. Lipoaspiração eu já fiz uns anos atrás, muitos anos atrás, eu já fiz uma lipo, acho que tava com 42 anos. Tenho medo agora, mas eu acho que faria, se tivesse num estado 'tenso', se eu não conhecesse a atividade física, que eu sei que posso melhorar meu corpo, com certeza eu faria." (Adriana, 51 anos, entrevista).

As demais alunas responderam que não fariam por medo de algo dar errado na cirurgia ou por não sentirem necessidade no momento:

"[...] Não, não tenho vontade de fazer cirurgia não, eu acho que é me arriscar muito sabe, eu nunca fiz, pode até ser, a gente nunca sabe o que vai ser o amanhã [...] A gente não tem que ser perfeita não, eu não quero ser perfeita, eu quero só ficar bonitinha e ser feliz (risos)." (Luísa, 57 anos, entrevista).

"[...] Morro de medo, mas adoraria. Queria colocar botox, mas depois vou ter que continuar e continuar... ah não, deixa assim. É a idade não se pode fazer nada, entendeu, eu adoraria fazer, mas não faria." (Rose, 55 anos, entrevista).

Embora tenham relatado negativamente sobre a questão das cirurgias, as falas das alunas indicaram desejo em realizá-las futuramente. Até porque o combate contra as rugas e os volumes indesejados já não se restringe aos regimes, aos exercícios físicos e aos artifícios da maquiagem. "Trata-se, doravante, de 'refazer', de remodelar a aparência ao desafiar os efeitos do tempo" (LIPOVETSKY, 1997, p.131). Vale destacar que o assunto

17 De acordo com o site de um especialista em cirurgias plásticas: http://www.drmoisesdemelo.com.br/. Acessado em 14 de Novembro de 2016. 
sobre as cirurgias plásticas é bastante difundido entre as conversas de corredor e/ou durante as caminhadas nas esteiras. As alunas trocam informações sobre o assunto, mostram os resultados obtidos e os respectivos médicos. Nesse contexto, pode-se afirmar que a academia se apresenta como um local de difusão e motivação desse tipo de intervenção, pois é ali que as alunas exibem seus corpos modelados pela ponta do bisturi.

\section{CONSIDERAÇÕES FINAIS}

Neste estudo buscou-se identificar e analisar os principais cuidados e investimentos no corpo a partir da observação e entrevista com mulheres frequentadoras de uma academia exclusiva da cidade de Vitória/ES. A relevância atribuída aos cuidados corporais se destacou na vivência cotidiana com as alunas na academia e nas análises dos relatos. Compreendeu-se, a partir dos valores investidos, que o público frequentador dessa academia possui condições financeiras privilegiadas. A alimentação, os exercícios físicos e os procedimentos estéticos foram os cuidados e os investimentos mais citados pelas entrevistadas. Esses cuidados estão vinculados à procura por esse tipo de academia, na qual se oferece orientação nutricional, treinos e exercícios personalizados para a mulher e, mesmo de maneira não intencional, apresenta-se como um expositor e divulgador das estratégias para se obter o corpo desejado. Não menos importante, destacou-se ainda o papel dos especialistas na vida das alunas, que, por meio dos seus conselhos remunerados, orientam os investimentos e os cuidados em benefício de um corpo perfeito.

Lipovetsky caracteriza o contexto contemporâneo ocidental como um momento marcado pelo consumo, insatisfação dos sujeitos, pela instantaneidade e flexibilidade dos hábitos, rotinas e formas de agir. Esses apontamentos levaram à compreensão sobre os altos investimentos das alunas em academias de ginástica, na alimentação, em procedimentos estéticos e na contratação de conselheiros. A insatisfação com o corpo e com serviços oferecidos promoveram a busca por uma academia que oferecesse um diferencial, um serviço e um atendimento personalizado para o alcance dos seus desejos "efêmeros". Nesse sentido, é preciso apostar em investigações sobre o surgimento e as constantes substituições de novas práticas corporais, produtos de beleza e dietas alimentares.

\section{REFERÊNCIAS}

AZEVEDO, I, R. Motivos de adesão à prática de exercícios físicos em uma academia exclusivamente feminina de Porto Velho-RO. 2011. 69 f. Trabalho de Conclusão de Curso. UNIR, Porto Velho, 2011.

BARDIN, L. Análise de conteúdo. Lisboa: Ed. Edições 70, 2009.

BAUMAN, Z. Modernidade líquida. Rio de Janeiro: Jorge Zahar, 2001.

. Tempos líquidos. Rio de Janeiro: Jorge Zahar, 2007.

BAPTISTA, T.J. R; ZANOLLA, S. R. Corpo, estética e ideologia: um diálogo com a ideia de 
beleza natural. Movimento, Porto Alegre, v. 22, n. 3, 999-1010, jul/set. 2016.

BORGES, P. J. et al. Acumulação flexível, técnicas de inovação e grande indústria do fitness:

o caso curves Brasil. Pensar a Prática. 10/2: 237-259, jul/dez. 2007.

DEL PRIORE, M. Corpo a corpo com a mulher: pequena história das transformações do corpo feminino no Brasil. São Paulo: Senac, 2000.

FISCHLER, C. Obeso benigno, obeso maligno. In: SANT'ANNA, D, B. Políticas do Corpo. São Paulo: Estação Liberdade, 1995.

FREITAS, C.M.S.M et. al. Aspectos motivacionais que influenciam a adesão e manutenção de idosos a programas de exercícios físicos. Revista Brasileira de Cineantropometria e Desempenho Humano, 2007.

FURTADO, R. P. Do Fitness ao Wellness: os três estágios de desenvolvimento das academias de ginástica. Pensar a Prática, Goiânia, 12/1: 1-11, jan/abr. 2009.

GOMES, I. M. Conselheiros modernos: propostas para a educação do indivíduo saudável. Tese de Doutorado, UFSC, Florianópolis, 2008.

. Obesidade como metáfora contemporânea: uma "Cruzada Saudável" em nome do consumo e do risco. Movimento, Porto Alegre, v.12, n. 03, p. 45-71, set/dez. 2006. LIPOVETSKY, G. A. Terceira mulher: permanência e revolução do feminino. Lisboa: Instituto Piaget, 1997.

. A Era do Vazio. Barueri, São Paulo: Manole, 1983.

LOVISOLO, H. Em defesa do modelo JUBESA (juventude, beleza e saúde). In: BAGRICHEVSKY, M. et al. (Org.). A saúde em debate na Educação Física. v. 2. Blumenau: Nova Letra, 2006.

MACEDO, T.T.S et al. Percepção de pessoas obesas sobre seu corpo. Escola Anna Nery Revista de Enfermagem. 19(3) Jul/Set 2015.

MARCONI, A.M, LAKATOS, M.E. Metodologia Científica. 5. Ed. São Paulo: Atlas, 2007. ORTEGA, F. Práticas de ascese corporal e constituição de bioidentidades. Cadernos Saúde Coletiva, Rio de Janeiro, 11 (1): 59 - 77, 2003. Disponível em: < http://www. cadernos.iesc.ufrj.br/cadernos/images/csc/2003_1/artigos/2003_1\%20FOrtega.pdf $>$. Acesso em: 18 mai. 2015.

SEVERINO, J.A. Metodologia do trabalho científico. 23. ed. rev. e atual. São Paulo: Cortez, 2007.

SANT'ANNA, D. B. (Org.) Políticas do corpo. São Paulo: Estação Liberdade, 2001.

TRIBESS, S. Percepção da imagem corporal e fatores relacionados à saúde em idosas. Florianópolis, 2006. 84 p. Dissertação (Mestrado em Educação Física) - Programa de Pós-Graduação em Educação Física, Universidade Federal de Santa Catarina.

Recebido em: Fevereiro/2017

Aprovado em: Junho/2017 